\title{
EL TERRITORIO COMO PUENTE ENTRE LA CULTURA Y LA POLÍTICA, PARTE II. EL PENSAMIENTO DE FEDERICO A. DAUS 1922-1957
}

\author{
Marcelo Ezequiel Lascano Kezic ${ }^{1}$ \\ Susana Isabel Curto
}

\begin{abstract}
Resumen: Se presenta un recorrido por el pensamiento de Federico A. Daus a través de su obra escrita, en especial hasta la aparición de "Geografía y unidad argentina", su obra cumbre. El orden cronológico provee un método preliminar para comenzar a distinguir componentes. Desde el comienzo puede verificarse un interés por el territorio como campo de especulación práctica. Luego su producción se adapta a las líneas humanistas de Museo Etnográfico de la Universidad de Buenos Aires. En la Universidad Nacional de La Plata profundiza la vertiente de la política de recursos naturales, a través de la geografía regional. Previo a la vinculación con el peronismo, Daus compone dos de sus piezas integrales, la Geografía de la República Argentina, publicada en España, y la primera parte de su Geografía de la Argentina, destinada a la enseñanza. Se produce una pausa en su producción hasta la aparición de "Geografía y unidad argentina", un planteo sobre el rol del territorio en la conformación de la Argentina. La vertiente práctica es abordada nuevamente, años después, a través de la temática del desarrollo, como combinación entre el perfil académico y cultural y la búsqueda de realizar una contribución a la vida del país a través del territorio.
\end{abstract}

Palabras clave: historia de la ciencia; Argentina; geografía; Daus; obra.

Summary: A summary of Federico Daus' thinking is presented through his written work, in particular that before the publication of "Geografía y unidad argentina", his most distinctive piece. The chronological order provides a preliminary method to outline a set of main issues. An interest on territory as a field for applied speculation may be recognized on his most early contributions. Afterwards, his work adapts to the humanistic lines of the Museo Etnográfico of the University of Buenos Aires. At University of La Plata he further develops a political understanding of natural resources through regional geography. Before his engagement with the peronist government Daus composes two of his most comprehensive works, the "Geografía de la República Argentina", published in Spain, and the first volume of his "Geografía de la Argentina", intended forsecondary school teaching. His production comes to a complete stop until "Geografía y unidad argentina", an analysis of the role of territory in Argentina's conformation. The prospective point of view is addressed one again in the following years through the idea of development, as a combination of cultural academic inputs and the search of making a contribution to national life through territory.

Keywords: history of science; Argentina; geography; Daus; thinking.

\footnotetext{
${ }^{1}$ Universidad de Buenos Aires. Facultad de Ingeniería. Escuela de Posgrado en Ingeniería Ferroviaria.

${ }^{2}$ CONICET/IIE Instituto de Investigaciones Epidemiológicas de la Academia Nacional de Medicina - Buenos Aires, susanacurto@yahoo.com.ar
} 


\section{INTRODUCCIÓN}

El pensamiento reflejado en la obra escrita de Federico Daus tuvo por objetivo asumir todo aquello relacionado con el territorio argentino, como lo ha señalado Randle (1988). La etapa más relevante de producción se desarrolló desde su graduación hasta el momento en que plasma un corpus conceptual integrado en "Geografía y unidad argentina", su libro más destacado, publicado en 1957. Analizaremos principalmente su pensamiento durante este período. Respecto a sus obras posteriores, haremos referencias a las piezas que extienden ideas ya expuestas antes de $1957 \mathrm{y}$, puntualmente, intentaremos sintetizar su incursión en la problemática del desarrollo.

Se procedió a la búsqueda y lectura de todas sus publicaciones (ver REY BALMACEDA, 1990). Se recopiló la totalidad de sus producciones. Este trabajo se llevó a cabo a lo largo de varios años, a medida que el material fue ubicado. Una vez emprendida la redacción de este artículo, se repitió su lectura. Se produjo un largo intercambio de pareceres entre los autores de esta contribución, precisando significados, estableciendo conexiones cruzadas entre distintas piezas y poniendo su pensamiento en el contexto de las instituciones desde las cuales se desempeñó.

Como primera cuestión debe prestarse atención a una característica de conjunto de la obra de Daus. Su legado escrito no es abundante. Al contrario de lo que ha sucedido con otros humanistas, que en sus áreas caracterizan una etapa, no contamos en este caso con una profusión de notas, comentarios, artículos y obras de múltiples volúmenes. Sin embargo, esto no significa que la importancia del personaje radique en su sólo rol institucional, a modo de entidad efímera que, por más que haya alcanzado manifestaciones intensas, pierde todo impulso y significado social apenas cesa el protagonismo individual. Daus unió una importante cuota de protagonismo personal con un pensamiento innovador sobre un rasgo poco atendido en la comprensión de la identidad colectiva en la Argentina - el territorio.

Si la obra no fue abundante, o no fue extensa, se hilvanó mediante enunciaciones compactas, densas, donde una lectura atenta puede identificar más de una premisa. En efecto, varios de sus escritos imponen un detenimiento y un ejercicio reflexivo intercalado; es algo que predomina en algunos de sus escritos más importantes. Podría ensayarse una explicación: la meta de asumir todo lo territorial se lleva bien con la búsqueda de síntesis y entonces, el pensamiento que presupone en el lector un amplio manejo de temas y personajes, apunta a sintetizar. Esto es trasversal a toda la obra de Daus, aunque en algunos de sus textos es menor la capacidad portante de las palabras y, por lo tanto, son de lectura directa. A fin de dejar en claro esta característica, 
puede señalarse el contraste de sus escritos, breves, con la extensión más generosa de los de su compañero de ruta, Romualdo Ardissone, pródigo en páginas y tinta para aparentemente dejar por sentado el itinerario completo de sus razonamientos en torno a un tema de estudio.

Como el presente artículo busca tan sólo delinear en forma preliminar su pensamiento, se decidió sistematizarlo en forma más o menos paralela con su trayectoria institucional, al menos para comenzar la exposición. Hacia el final intentaremos identificar algunas temáticas que persistieron o que conceptualmente fundamentaron otras. Nuestra intención es realizar una primera aproximación, ya que observamos que algunas contribuciones de Daus podrían merecer un estudio individual. Se encontrará el lector aquí con un primer paso, entre otros posibles, para la comprensión de su legado.

\section{Desempeño inicial en la Universidad de Buenos Aires}

En esta época Daus actúa desde un ámbito fuertemente volcado hacia la antropología y la arqueología, a las cuales realiza aportes. Sin embargo, es interesante insistir en que se trata de una adaptación al medio. En la monografía sobre la cuenca del río Negro, que presenta para ingresar a la cátedra de Geografía Física, escrita durante 1927 (DAUS, 1927), el interés está en el territorio como entidad política que puede comprenderse desde una prospectiva de los recursos naturales. Seguidamente analizaremos este aspecto. El primer capítulo de este escrito versa sobre los exploradores del área. Esto distingue el punto de vista respecto de, por ejemplo, una memoria de inventario geológico que puede concentrarse exclusivamente en el funcionamiento mecánico de la naturaleza, o la de un análisis hidráulico avocado a la cuantificación de la existencia de agua. Al incluir el estudio de los exploradores, Daus pone el tema en el plano de la historia, y por lo tanto de la política. Y lo hace al comienzo de la monografía de forma que, la información consignada a continuación, queda ya inserta en una perspectiva práctica. El territorio posee recursos naturales, y estos puede ser objeto de reflexión colectiva. El inventario de los recursos naturales no deja de presentarse; aún más, es exhaustivo pero ya asociado al potencial uso o explotación. Se intenta poner la información a disposición de potenciales usuarios, estableciendo un puente entre la política y la sola perspectiva técnica. En este sentido, es interesante comparar este trabajo de Daus con los aportes similares que entonces realizan destacadísimos autores como Pablo Groeber y AugustoTapia, geólogos, o Francisco Romero, ingeniero. Próxima a esta 
perspectiva integradora está la gran obra de Antonio Soldano (1947), todos socios de G/EA Sociedad Argentina de Estudios Geográficos.

Este carácter doble, prospectivo y cultural, quedó en verdad ya identificado con el análisis de la trayectoria institucional de Daus (LASCANO y CURTO, 2013). Vemos ahora cómo ése carácter estuvo presente desde un comienzo. La incursión de Daus en los temas del Museo Etnográfico de la Universidad de Buenos Aires (UBA), se desenvuelve manteniendo latente el interés por el desarrollo territorial. En esta monografía también puede advertirse el interés por los grandes espacios, en marcado contraste con la escala de trabajo de la arqueología puntual del Museo, o de la geografía humana de Ardissone.

Sin duda fue el ascenso de Félix Outes, y sobre todo, de Francisco de Aparicio, lo que sustentó las contribuciones de Daus cercanas a la etnografía, en las que el centro es la persistencia de costumbres ancestrales en un país donde la modernización ya había cubierto gran parte del territorio. Si fuera necesario encontrar una transición entre la monografía de 1927 y la producción posterior, la ofrece su segunda publicación, de 1936 (VIDIRI y DAUS, 1936). Allí, en coautoría, un joven Daus analiza para la Comisión Nacional de la Vivienda, la habitación en los obrajes forestales y su implantación ambiental, relevados con trabajo de campo en el Norte de Santa Fe.

En varios artículos hace referencia a los géneros de vida, luego de enumerar las condiciones ambientales. Esta línea de trabajo tiene por objetivo identificar las modalidades de la cultura como emergentes del entorno, y de la organización de las actividades humanas condicionadas por los recursos disponibles. Estos escritos transmiten un punto de vista netamente vidaliano: los condicionantes ambientales como concausas. Por ejemplo, refiriéndose a los que denominará oasis pobres:

"Así vemos que mientras 230 kilómetros de cordillera nevada rezuman sus deshielos para formar un solo oasis rico, el de San Juan, los 120 kilómetros lineales de la sierra de Famatina desprenden una veintena de arroyuelos y ríos, a que corresponden sendos oasis pobres. El resultado es un desmenuzamiento de las posibilidades de instalación del hombre." (DAUS, 1944, p. 53)

Y agrega más adelante:

"En Chilecito y en el Valle de Catamarca la subdivisión de la propiedad ha alcanzado la línea roja de peligro....Ya se está en condiciones de atomización en que el trabajo es antieconómico y como el proceso de subdivisión no se detiene por razones demográficas, no se ve que la colectividad pueda subsistir..." (DAUS, 1944, p. 59) 
Estas observaciones son posteriores a un estudio en el que abordó detalladamente la hidrología de la misma región (DAUS, 1938). En cuanto a estos fragmentos de 1944 merece destacarse el acento puesto en el desarrollo territorial condicionado por un esquema ambiental puntual pero regionalizado por repetición. En este mismo artículo Daus se refiere a la pertinencia de obras de infraestructura, detalle que pone su análisis en el plano de la aplicación. Dicho con términos que utilizará Daus mucho después, la geografía como disciplina capaz de aportar al desarrollo. En una monografía sobre los bosques del Chaco (DAUS, 1940b) incluye un apartado titulado "reflexiones sobre el futuro de la explotación", incursión pionera en un contexto en que los autores textos de geografía se limitaban a la compilación de tablas de datos de producción y población (por ejemplo, BOERO, 1933; G. DE GUTIÉRREZ, 1929; SABÍN PAZ, 1945).

Si hubiera de buscarse un corte, un cambio neto entre la línea del Museo de la UBA y la comprensión del territorio como espacio potencial, podría ubicarse en "Transhumancia de montaña" (DAUS, 1948a). En este artículo conviven la perspectiva del observador exógeno sobre una práctica (la transhumancia) fuertemente marcada por un condicionante ambiental (la estacionalidad), con la referencia a innovaciones tecnológicas que lo superan. Esta es la última contribución en la que Daus aborda la descripción de costumbres seculares con la lente del habitante de la gran ciudad cautivado por lo pintoresco, pero ajeno a lo descrito. Este artículo es de 1944 y puede adoptarse como la clausura de una etapa.

\section{La "gran escala" durante la etapa temprana}

Si bien, institucionalmente, Daus creció en un Museo "Etnográfico y antropológico", desarrolló en forma paralela otro interés más marcado: tratar problemas territoriales a gran escala. Ya mencionamos la monografía sobre el río Negro, que redactó con apenas 26 años. La que puede considerarse su primera publicación (DAUS, 1935) intenta presentar el territorio argentino en forma sintética. En este artículo aparecen entrelazados varios temas: la especificidad de la ciencia geográfica, el concepto de región y la necesidad de facilitar la enseñanza, dejando de lado la mnemotecnia que resulta de presentar el territorio mediante cortes temáticos de las ciencias auxiliares. Sin duda, un plan ambicioso para desarrollar en un sólo artículo.

En este escrito Daus comienza separando la diferenciación paisajística de la síntesis regional. De esta forma propone la superación del nivel descriptivo, entendida como una lectura de paisajes naturales. 
"El estudio regional puede abordarse en diversas escalas. Con un criterio convenientemente prefijado, podemos considerar, por ejemplo, a la región del N.O. argentino -Salta, Jujuy y Los Andes- como una unidad o bien el valle del río San Francisco, que la integra. En cualquier caso, el análisis regional se cumplirá por correlaciones locales. Dentro de la región N.O., la cuenca mencionada se caracteriza por elementos fisiográficos y antropográficos bien perfilados, con sus sierras subandinas limítrofes, su clima de tipo "tropical", sus formaciones fitogeográficas de selvas, sus plantíos de caña ... de todo lo cual resulta un determinado tipo de ocupación humana, géneros de vida, formas de vivienda; las agrupaciones urbanas cobran tinte local identificable: sus relaciones de vecindad contribuyen a explicar las corrientes de población que han venido a componer sus elementos étnicos. La correlación circunstanciada de todos esos hechos dará a la reseña regional modalidad propia, desde que ya no será una yuxtaposición desarticulada por la necesidad de considerar simultáneamente varios complejos geográficos distintos." (DAUS, 1935, p. 91)

De este párrafo es interesante rescatar dos nociones utilizadas: la de "correlación" entendida como la conexión in situ de procesos genéricamente distintos, y la de "relaciones de vecindad" entendida como primigenia concepción de posición. Daus logra de esta manera llamar la atención sobre aspectos diferentes a los contenidos propios de las disciplinas sistemáticas, conectados con la idea de "armonizar los conocimientos dispersos susceptibles de coordinación", que ya expone en su monografía sobre el río Negro. En este mismo artículo formula un criterio metodológico que, en nuestra opinión, será el que usará en su obra:

“...un tópico que en la enseñanza de la geografía adquiere un volumen excepcional: el estudio de las ciudades. Cómo lo hacen uno y otro sistema [refiriéndose al corográfico, por cortes, y al regional, N.d.A.:]. En uno (...) se las menciona comenzando por las de rango político y se completa la nómina de las "importantes" por el número de habitantes, con vagas impresiones de su localización, de su significado económico y cultural. (...) Nada más próximo al catálogo de nombres y datos". (DAUS, 1935, p. 94).

Años después, en el diálogo con colegas y discípulos, Daus insistirá sobre esta diferencia, haciendo referencia a "la amena geografía de los lugares y las cosas". En este mismo artículo de 1935, enuncia un camino superador:

"En el estudio regional, en cambio, la aglomeración urbana surge como un producto ambiental característico, localizado por razones históricas, económicas, o por su posición fluvial u otras causas estudiadas simultáneamente". (DAUS, 1935, p. 94). 
El esquema de ciudades "engranaje", que después delineará en "Geografía y unidad argentina", parece expresar este criterio. A los fines de un análisis del concepto de región en la obra de DAUS, resulta de interés comparar este artículo con los que publicará en 1969, en los que precisa un criterio para cada región de su cuadro del territorio argentino y, en marcado contraste, enfatiza el carácter sólo metodológico de la geografía regional (Daus 1969b, 1969c).

También otro grupo de artículos se alinea en la perspectiva de la gran escala. Daus aborda el poblamiento del territorio continental americano en dos contribuciones (DAUS, 1939, 1945) y es autor de un capítulo dedicado a la geografía de América en una obra conjunta dirigida por el historiador Ricardo Levene (DAUS, 1940a). En su publicación sobre la inmigración y la expansión agropecuaria (DAUS, 1939) puede observarse la articulación entre un problema de conjunto, y las regiones como herramientas. Allí se plantea los pasos para evitar las exageraciones en el cálculo de las hectáreas cultivables en el territorio argentino:

\begin{abstract}
"Sobre posibilidades en realidad dudosas, sobre riquezas no inventariadas, sobre recursos no computables pero tenidos por existentes, se cifran esperanzas, se propugnan rumbos para la política demográfica, inmigratoria y económica, que van hacia el fracaso inevitable. (...) Y cuando nos ponemos ante el problema de la pobreza estereotipada de ciertas regiones o al desierto de un parte harto grande de nuestro suelo, no advertimos que estamos ante problemas de raigambre geográfica y los cargamos a la cuenta de la incuria de los gobiernos, a la inopia de los "criollos" o a la ausencia de población." (DAUS, 1939, p. 7).
\end{abstract}

Este estudio excede el tema agropecuario abordando los aspectos sociológicos y demográficos resultantes de la preocupación pública de entonces por retomar las políticas inmigratorias. Aquí lo regional aparece como un recurso metodológico, concurrente pero el problema planteado es de conjunto. Concluye señalando:

“...el aumento de población debe buscarse: por el fomento de la actual, mediante un ordenamiento económico-legislativo que propenda a la adquisición de la tierra por quienes la trabajan, a la división de los latifundios y a crear oportunidades de trabajo para los hombres." (DAUS, 1939, p. 21).

No puede cerrarse el análisis de esta primera "etapa" sin hacer referencia a su visión sobre el ambiente físico. Surge aquí, sin embargo, un contraste: si bien el principal anclaje institucional de Daus desde 1928 es la cátedra de Geografía Física, son pocos sus trabajos en este campo. En 1938 publica un análisis de escala puntual de problemas de erosión retrocedente en la región árida argentina. Hacia 1940 (GEA actas III, 5) tiene lista su "Morfografía general de las llanuras argentinas" (DAUS, 1946), que constituirá uno de los capítulos del tomo III de la Geografía de 
G/EA. En una primera parte de este trabajo presenta rápidamente un inventario de los llanuras del país, puntualizando diferencias mediante la mención de paisajes, para luego, en una segunda parte, presentar su vinculación con la geología estructural. Aquí también se hace referencia a los patrones de escurrimiento. Sin embargo, se trata de una línea de trabajo a la cual no volverá, salvo en su trabajo de 1950 (DAUS, 1950), a pesar de su cátedra. Muestra en estos dos artículos, una gran capacidad expositiva, cuando el tema comenzaba a ser estudiado, si se toman en cuenta los trabajos posteriores de Alfredo Castellanos (1961), Pierina Pasotti (1972) y Eliseo Popolizio (2003).

\section{El paso por la Universidad de La Plata: el territorio de la mano de la economía}

La incorporación de Daus al plantel docente de esta universidad dará lugar a dos de sus más importantes monografías regionales. Se trata de las que dedica a los bosque del Chaco (DAUS, 1940b) y al cultivo de cereales (trabajo listo en 1942 pero publicado en 1945).

Respecto a la primera destacamos que, desde su mismo título, se dirige a los recursos naturales. No al regionalismo cultural basado en vestimenta, lenguaje o rastreo del origen profundo de la identidad del gaucho o sus costumbres. La atención está en el presente. Se organiza un cuadro integrado del funcionamiento del territorio, comenzando por señalar que:

“...su explotación [N.d.A: del bosque] ha constituido el mayor aporte de las florestas a la economía argentina y ha promovida la más intensa actividad devastadora e industrial de esta especie. Además, la explotación despiadada (...) ha originado transformaciones en las sinecias, que comportan un cambio radical en los coeficientes de estimación económica..." (DAUS, 1940b, p. 140)

A continuación, la redacción sitúa al lector en el ambiente físico y la dinámica funcional de la extracción de madera, sus distintas modalidades y los actores sociales. Se suman las circunstancias simultáneas de una economía regional. Se trata de un texto extenso, pero a este fin es difícil pensar que consigna datos o aspectos innecesarios o accesorios. Una vez recorrido esta primera parte del artículo, se está, ahora sí, en condiciones de comprender los problemas de esta actividad. Daus entonces presenta la crisis del sector:

“...algunas naciones interesadas había implantado un fuerte impuesto al extracto de quebracho argentino, en tanto que gravaban en forma comparativamente leve la introducción de rollizos" (DAUS, 1940b, p. 180)

El mérito en esta monografía es lograr transmitir el impacto en el sistema territorial, en cada una de sus partes, de la alta exposición de la actividad al mercado internacional,. Finalizada la lectura, 
queda establecido cómo el poblamiento de una extensa porción de nuestro territorio figuraba sujeto a los vaivenes diplomáticos o a la discrecionalidad de mercado. Así, se presenta de forma realista las condiciones de la explotación forestal.

La atención que puso Daus en la utilización de los recursos naturales puede también reconocerse en su contribución para el Colegio Libre de Estudios Superiores (DAUS, 1940c), donde presenta los principales ítems - minerales, marinos, ecológicos - junto con una valoración de su potencial. Una geografía física en clave económica. Como ya adelantáramos en la trayectoria institucional de Daus, este artículo posee un valor excepcional, primero como representativo de su llegada a ámbitos extra-académicos donde el conocimiento tuviera un rol activo y aplicado. Aquí observamos además cómo este artículo constituye una pieza sui generis: se aparta del cientificismo omnipresente en los estudios del medio físico, sin caer en la mera enumeración de datos y valores monetarios. Está planteando la comprensión del territorio, y simultáneamente, en forma implícita, perfilar el campo de estudio de la Geografía. La especificidad que en 1935 se proclama atada a lo regional, se encuentra aquí planteada desde el tema de los recursos naturales. Es ésta, en verdad, y no el sólo cuadro regional, la temática que desarrolla en cuanto a los bosques del Chaco y el cultivo de cereales.

Daus se refirió, mucho después, a esta subordinación de lo regional. Fue durante el simposio sobre la definición y la enseñanza de la Geografía, realizado en 1967, que, en nuestra opinión, fue la reunión de discusión sobre la epistemología de los estudios territoriales más amplia e importante de la Argentina de entonces. Daus debió advertir que la parte se tomaba por el todo, y afirmó en esta ocasión la autonomía metodológica de los estudios sistemáticos en la investigación científica:

"En el tratamiento de la metodología regional parece conveniente hacer una aclaración preliminar. Se ha de hablar en este escrito de un plan regional para la enseñanza media y de una didáctica correlativa. Pero nada de eso se extiende a la investigación geográfica, en que la preocupación regional no constituye una opción excluyente. La investigación geográfica sobre temas particulares debe estar imbuida de espíritu regional, o sea, por la preocupación por indagar procesos de lococonexión. Pero ello no implica que deba estar sujeta a ningún cartabón de división regional. Por el contrario, el tipo de investigaciones llamadas tópicas desempeña un papel irremplazable en el progreso de la ciencia geográfica y rige, naturalmente, la más completa libertad de planificación ". (DAUS, 1969a, p. 46)

En el mismo texto Daus es aún más explícito, y define el alcance del método regional primero como instrumental, y luego, como didáctico:

"...el plan regional debe ser puesto en práctica como un medio para enseñar racionalmente la geografía pero no es un fin en sí mismo." (DAUS, 1969a, p. 46) 
Creemos que estas afirmaciones explican la convivencia entre la fuerte afirmación metodológica de 1935 con los planteos prácticos o aplicados de los trabajos de 1939 y 1940.

Pero esta línea práctica o propositiva tiene corta vida, por el involucramiento de Daus en roles institucionales durante el peronismo. En algún momento de la transición hacia su vinculación con la política, redacta su "Geografía de la República Argentina", su obra más extensa, publicada en 1948 en el tomo XXII de la "Geografía Universal" dirigida o denominada como compilada por Vidal de la Blache y Gallois, en su edición en español, dirigida por Vilá Valentí (DAUS, 1948b). En poco más de trescientas páginas desarrolla un encantador recorrido por todo el territorio continental americano de la Argentina, organizado regionalmente y alternando entre las consideraciones de conjunto y la aproximación a las subregiones o comarcas. El texto se presenta de fácil lectura, e integra la síntesis con el inventario informativo. Es una verdadera geografía integral, sin apuntar a un mayor nivel de abstracción, pero trasluciendo la clara intención de organizar la información y su valoración. A lo largo de todas sus páginas está presente la cuestión del desarrollo territorial: la explotación de los recursos naturales, los asentamientos en red y la infraestructura. Tal vez el mayor mérito sea presentar estos temas sin tecnicismos que impongan un perímetro infranqueable para el lector no especializado. Aquí radica la capacidad que tuvo Daus para transformar en cultura los problemas de carácter público, así como de la misma manera proyectó elementos de la cultura hacia el plano político a través de su trayectoria institucional.

Si bien en esta obra el estudio del país se organiza regionalmente, se dedica al mismo tiempo una cantidad importante de páginas al análisis de temas en forma conjunta. Al comienzo de la último capítulo se incluyen algunas observaciones sobre el origen histórico del territorio. Es aquí la única ocasión en la que Daus se refiere explícitamente a figuras de la historia política, cosa que no hará en "Geografía y unidad argentina". Esta "Geografía de la República Argentina" se publicará en tres ediciones más: en 1949 como parte de una "Geografía de América", de la editorial Montaner y Simón, y luego, las dos colecciones la reeditarán en 1957, parcialmente actualizada.

Es también entre 1940 y 1947 que escribe la primera parte de su geografía para la enseñanza. En 1945 aparece "Geografía de la Argentina I: parte física" (DAUS, 1945b). La parte humana aparecerá recién en 1953. Estos manuales muestran un manejo diferenciado de los niveles de lenguaje por parte de Daus. Aquí la exposición sigue un orden claramente escalonado, con secciones cortas, cuadros de datos y, particularmente, numerosos mapas y fotos. En cambio, en 
"Geografía y unidad argentina" Daus demandará mucho más del lector, al transitar el extremo opuesto de la escala de abstracción.

A partir de 1945 la producción de Daus se enrarece, limitándose a algunos artículos más o menos importantes y breves contribuciones, que no introducen novedades en el pensamiento expresado en sus publicaciones previas. En 1956 el Instituto Panamericano de Geografía e Historia publica su "Fisonomía regional de la República Argentina", que luego será su trabajo con mayor cantidad de ediciones. Aparecerá reeditado después en otras tres ocasiones y reimpreso otras tantas. Nos permitiremos aquí señalar la desproporción entre la difusión que tuvo este texto en relación a su importancia relativa en el total de la obra de Daus. Las múltiples ediciones pueden inducir a una sobrevaloración de su contenido. También la multiplicación de sus textos de enseñanza, sobre todo a partir de fines de los '60, donde el recurso regional es prioritario, puede conllevar este efecto. Los elementos rescatados en este estudio van en otra dirección. Hecha. esta aclaración, puede pasarse a una valoración preliminar de "Geografía y unidad argentina".

\section{Ya fuera de la universidad: "Geografía y unidad argentina"}

En los primeros días de junio de 1957 se encuentran confeccionados los primeros ejemplares de esta obra, clave de bóveda del pensamiento de Daus (DAUS, 1957). La Enciclopædia Britannica la consigna en la breve lista de referencias al final del artículo sobre la Argentina (BRITANNICA, 1981a). Descontado el tiempo que pudieron consumir el armado y correcciones de galeras, puede estimarse que el libro está listo en los primeros meses de 1957. Es, luego de la "Geografía de la República Argentina", su primer aporte incisivo en largo tiempo.

El libro propone un estudio de la importancia del territorio en la conformación de la unidad nacional. Como se puntualiza en la introducción, este tema ha sido campo de los historiadores y falta una valoración sobre la incidencia del territorio. Daus se mantiene inexorablemente fuera de la historia política a lo largo de todo el libro, restricción de difícil consecución para un tema hasta entonces trabajado exclusivamente desde la historia política.

El problema se plantea sin rodeos en las primeras páginas. Durante más de dos siglos y medio se configura un espacio funcional en el territorio que constituyó la jurisdicción del Virreynato del Río de la Plata. A continuación Daus expone dos rasgos de este proceso, el cual se produce: 
Agrega inmediatamente que:

“...se trató de un proceso histórico, ininterrumpido y espontáneo..." (DAUS, 1957, p. 1).

Aquí es oportuno detenerse e indagar pausadamente sobre la definición del problema que el autor propone abordar. El primer rasgo destacado es críptico y al mismo tiempo quizás el más relevante para seguir el razonamiento que sostiene toda la obra. Proponemos aquí una interpretación a través de la lectura repetida del texto. Al recurrir al término "época" Daus está refiriéndose a un período histórico determinado, al período Indiano-Hispánico. El poder político al que engloba a todo el cono Sur es el mismo. El establecimiento espontáneo de líneas de tránsito de personas y mercaderías entre los asentamientos, puertos y trastierras responde al establecimiento progresivo de los itinerarios más fáciles. La consolidación de los caminos Virreynales es el resultado en el que predomina la prueba y el error de los conductores de diligencias y caravanas. Esto significa que el territorio político total se hace heterogéneo no por el establecimiento de parcelamientos administrativos, sino por el criterio práctico. En tanto y en cuanto se mantuvo la pertenencia política común - España - durante dos siglos y medio, la emergencia de "espacios funcionales de frecuentación" se produjo en forma ininterrumpida y espontánea.

Este aspecto lo ilustra con el ejemplo del Corregimiento de Cuyo, el cual se dirige al centro de esta distinción: el límite administrativo que cortó un espacio funcional es corregido por la metrópoli, a pedido de los propios pobladores. La subdivisión empírica del territorio se impone a la emanada de fuentes distintas a la experienia. El nuevo límite administrativo, que no alcanza rango político porque en definitiva, es la misma España la que está a ambos lados, se ajusta así al espacio para el cual Daus utiliza el término "natural", pero no a modo de territorio virgen. El espacio natural de Daus es aquél territorio integrado sobre la base de la facilidad en las comunicaciones, que se da en forma espontánea.

Puede notarse aquí una diferencia radical con el rol atribuído desde la historia a la geografía. Daus no se referirá a tal o cual rasgo paisajístico que pudiera haber dirimido esta u aquella batalla. "Geografía y unidad argentina" no cumple ese poco ambicioso, aunque repetido, papel de la descripción de los escenarios de las grandes batallas. Y aquí radica su originalidad: inserta el territorio en la línea del tiempo. Puede insistirse un poco más sobre este punto. En efecto, podría decirse que condensa en un solo corte la historia del territorio, en particular en este caso, la historia del despliegue espacial del poblamiento y su integración funcional. Queda clara la 
distancia existente entre esta perspectiva y la descripción visual de un valle, con sus desfiladeros y río episódicamente bravo, a modo de pintor que busca disponer un fondo en la tela donde el primer plano lo ocuparán los personajes históricos.

El estudio de la conformación de la unidad política de un país excede ampliamente, el rol jugado por el territorio donde ocurrió, al cual se encuentra indisolublemente asociado. $\mathrm{Y}$, al mismo tiempo, el sentido colectivo tampoco constituye un empecinamiento en lo propio en tanto propio. Es, en este sentido que, hacia el final de la introducción, Daus encuadra su planteo en una axiología:

“(...). La universalización de la vida internacional a que se asiste en nuestro tiempo presagia, ciertamente, no pocas restricciones en los conceptos vigentes sobre independencia de los Estados, y a este respecto no cabe dudar de que, en todo caso, las naciones que mejor hayan logrado consolidar su unidad interna se hallaran más favorecidas en su participación en la cada vez más absorbente vida internacional. (...)."(DAUS, 1957, p. 24).

Poco después agrega:

"La unidad en lo antropogeográfico involucra múltiples aspectos problemáticos sobre los cuales es incierto formular reglas de valor general y permanente. Naciones hay cuya unidad parece ser muy firme en lo antropogeográfico, especialmente en el aspecto cultural, y ofrecen, sin embargo, ejemplos de grietas en lo étnico, lingüístico o religioso. Las naciones americanas, no obstante su carencia de algunas de estas facetas de la unidad, sugieren la existencia de una vigorosa unidad espiritual en gestación. A pesar de estas contradicciones que denotan la dificultad existente para definir con precisión la faz espiritual de la unidad, podemos decir que ella, en términos generales, tiene por base el estado sublimado de comunión del hombre con la tierra en un espacio geográfico singular, en virtud del cual adquiere conciencia colectiva de individualidad. Se la puede describir como una identidad entre los habitantes en cuanto a sentimientos básicos, tendencias y manera de encarar las cosas comunes, creadora de un estado de conciencia general que une a todos en los mismos anhelos y propósitos fundamentales." (DAUS, 1957, p. 25).

Los elementos contenidos en estos dos fragmentos se relacionan con la identidad política, temática en la cual se inserta el libro. Es cierto que Daus no utiliza el término "identidad política". Sin embargo, habla de la unidad en sus distintas facetas, esto es, una categoría colectiva equivalente. La clave está en la formación de lo colectivo, que incluye el territorio, en la historia. Es difícil establecer una distinción entre estos elementos y el estudio de una identidad política.

Desde este punto de vista es que se comprende la distancia que Daus toma respecto de la unidad nacional como "una fuerza moral construída sobre la voluntad de tornar victoriosa una idea", definición que toma prestada del intelectual y político inglés Harold Laski (BRITANNICA, 1981b), de 
inicios en el comunismo y que finalizara su carrera pública militando en el liberalismo económico. Esta cita, al igual que los enunciados iniciales sobre la libre y espontánea incidencia de los factores geográficos, definen el basamento epistemoglógico sobre el cual está construido todo el planteamiento: un país se origina en un proceso históricamente significativo, sobre el que intervienen actores con capacidad para incidir en forma protagónica pero no como factores excluyentes de control, por cuya voluntad se torna victoriosa una idea. Es decir, la nacionalidad no surge como su deseo, capricho, u obstinación arbitraria. Si así fuera, la unidad se transformaría en una entidad ceñida a lo aleatorio sin posibilidades si quiera de poseer significados propios o diferenciables, o incluso, ya colocados en un plano de escepticismo, sin posibilidad de atribuirle un valor positivo. Al dedicarles un libro, Daus la considera como positiva. Y, a partir de las definiciones que presenta, la considera un proceso múltiple. "Geografía y unidad argentina" analiza cómo gravitó el territorio en el caso del proceso histórico argentino.

Este libro es merecedor de un estudio individual, que excede una primera valoración general del pensamiento de Federico Daus. Su enfoque es heterodoxo: intenta individualizar el rol del territorio en un proceso multi-causal. Existen dos obras sobre el espacio territorial Virreynal cuyos enfoques permiten establecer la relación entre el enfoque de "Geografía y unidad argentina", con aquél de la historia, desplegado enteramente sobre la línea de tiempo. Siendo docente de la Facultad de Humanidades de la Universidad de La Plata, Daus seguramente tuvo conocimiento inmediato del "Don Pedro de Cevallos" de Enrique Barba (1978), donde se presenta el rol jugado por el ilustre gobernador de Buenos Ayres en la conformación del Virreynato. Este excelente estudio no figura en la bibliografía de la obra, en forma coherente con la total ausencia de menciones a personajes históricos. Existe una segunda obra, pero de 1967, de Sergio Villalobos, que presenta una cronología en la evolución de las comunicaciones marítimas y terrestres desde y hacia Buenos Aires durante el siglo XVIII. A diferencia del estudio de Barba, este libro no indaga en la historia política, pero sí en las modalidades y los cambios en la circulación de mercaderías.

Puede establecerse una escala creciente de protagonismo del espacio, desde el "Don Pedro de Cevallos", pasando por el "Comercio y contrabando en el Rio de la Plata y Chile" de Villalobos, hasta "Geografía y unidad argentina". Y cabe preguntarse si el estudio de la incidencia del territorio en la unidad de la Argentina necesita recorrer el itinerario de estos dos libros o, contenerlos como axiomas desde los cuales alcanzar un mayor nivel de abstracción. Después de todo fue hacia este aspecto que se dirigió la recensión del libro que hiciera Zamorano, recién publicado (Zamorano, 1958). Creemos que el planteo de Daus los integra y produce una 
ampliación de la comprensión de los orígenes del Río de la Plata como espacio geohistórico. Las persistentes referencias a la circulación en el territorio, así como la consignación de fuentes tales como las compilaciones de De Angelis suponen en el lector un manejo no casual de los conceptos de la historia mercantil y política del siglo XVIII. De ahí también que su lectura no sea accesible como un primer paso.

El contenido de "Geografía y unidad argentina" amerita un transmisor, que despliegue sus ideas, como Mumford hizo con las de Patrick Geddes (HALL, 2002). Las ideas allí vertidas presentan una coherencia granítica, pero han visto la luz bajo la forma de afirmaciones extremadamente intrincadas, merecedoras de un Mumford. En verdad, el tema amerita tal estilo: lograr la convivencia de datos y observaciones del más diverso tipo, tal como coexisten materia y significados, co-localizados en la realidad total. Este libro combina secciones de naturaleza técnica, con pasajes netamente estéticos, que sitúa al lector casi en la vivencia de un paisaje, como sucede en la presentación de la región patagónica, la página más lograda en este sentido, hecha mediante un recorrido por los cinco sentidos

Probablemente sea más fácil encarar la lectura de "Geografía y unidad argentina" pasando primero por algunos textos posteriores que amplían algunos de sus conceptos clave tales como "La transformación del paisaje natural en paisaje cultural antes de la Revolución de Mayo" (DAUS, 1961), su "Geografía de las fronteras" (DAUS, 1966, 1967a, 1967b, 1967c), "La conciencia territorial y su raíz geográfica" (DAUS, 1978) y, una de sus últimas publicaciónes, "El ámbito pampeano" (DAUS, 1981).

\section{Después de-"Geografía y unidad argentina"}

En 1962 aparece "Viajeros, exploradores y sociedades geográficas" (DAUS, 1962a), quizás uno de los mejores artículos de Daus. Allí se presenta una historia del conocimiento geográfico del mundo, en la etapa de los grandes descubrimientos, mediante varias tipologías de viajeros, exploradores y científicos. Impreso con una tipografía minúscula, el texto provee un resumen claramente redactado, y muestra una gran creatividad para desarrollar con criterio propio un tema que podría consultarse en cualquier enciclopedia. Revela al mismo tiempo el perfil profundamente cultural de Daus. El prólogo a la obra de Rey Balmaceda (DAUS, 1976a) parece continuar este mismo texto. Cabe comentar aquí su poca continuidad, la poca articulación con el contenido de 
"Qué es la geografía" (DAUS, 1962b), otra obra de Daus editada una cantidad de veces no necesariamente acorde con la precisión de los conceptos allí abordados.

Posteriormente, con la aparición de 'El desarrollo argentino' (DAUS, 1969b) comenzó una serie de publicaciones referidas a la temática del desarrollo. Este primer libro, que tuvo cinco ediciones, consta de tres partes. La primera trata la historia económica de la Argentina, desde la etapa que denomina 'el ciclo de la sociedad tradicional' (concepto que toma de Rostow), pasando por el régimen conservador de las décadas del '30, del '40 y la posguerra. Luego hace un análisis comparativo entre países con diferentes indicadores de desarrollo y, por último, traza las líneas de un programa general de acción tendiente al desarrollo. Entre las reflexiones iniciales puede leerse:

"Si se examinan las condiciones en que pueden procurarse, por una planificación de base geográfica, un desarrollo genuino en la República Argentina (...) no se podrá prescindir de la discriminación regional. No cabe duda que el programa de fomento de la infraestructura (...) debe ser amplio en todo el territorio, por que el compromiso del desarrollo debe asumir la inasible diversidad que exigen tantas condiciones regionales dispares y contradictorias. Por esto se impone el programa de regionalización en su máxima expresión, como es, precisamente, la formulación de un mapa de cinturones para la agricultura especializada y la integración industrial del caso" (DAUS, 1969b, p. 18).

La primera parte de esta cita es un reconocimiento de la diversidad del territorio argentino Esta diversidad obliga a tomar medidas particulares para elaborar propuestas de planeamiento según cada caso, pero siempre integradas a una visión general de escala nacional. En esta publicación Daus aplicó aquello que señalaba en su artículo de 1961, en el que puede encontrarse la enumeración de una serie de principios generales para la concepción de estrategias de desarrollo económico. Uno de los que merece ser destacados es el siguiente:

“En la Argentina, el espacio geográfico de mayor aptitud para una producción masiva de calidades especificadas es la pampa (...). Como región nuclear del territorio se halla en condiciones de propagar concéntricamente su impulso de crecimiento (...). Ejemplos en esta dirección argumental abundan en referencia a los países que han cumplido el proceso [impulso inicial hacia el desarrollo pleno] en tiempos recientes. Canadá tiene la industria del papel para bovinas y de pulpa que es (...) el pilar de crecimiento en el que ese país ha quemado etapas; esa actividad industrial está basada en la concomitancia territorial entre los bosques de pinos y ríos correntosos de aguas claras que suministran hidroelectricidad energía barata - y acceso directo a las vías de comunicación internacional" (DAUS, 1969b, 89)

En este tramo Daus reafirma ideas ya expresadas en 'Morfografía general de las llanuras argentinas' y en 'Geografía y unidad argentina', aunque en un plano no ya explicativo, sino prospectivo. Algunas páginas más adelante señala: 
"No hay ejemplos válidos de países que hayan logrado tomar la altura de vuelo del estado de desarrollo sobre la exclusiva base de la agricultura común (...). Se podrán hacer planes para aumentar la producción actual y posiblemente se llegará a ello, con lo cual las exportaciones habrán de alcanzar cifras que dupliquen las que alcanzan al presente. Pero mientras los beneficios resultantes no se difundan extensivamente en el sector industrial para fortalecerlo y diversificarlo, en forma de inversión específica, no habrá propulsión para el desarrollo" (DAUS, 1969b, p. 138).

Respecto a la estructura agrícola argentina Daus pintó un cuadro prospectivo con elementos de los cuales hoy algunos continúan presentes. Según puede leerse, las condiciones fundarias en la Pampa y la falta de dinamismo en la cultura de los propietarios pone de relieve la mayor tecnificación y diversificación de los ámbitos rurales extra-pampeanos de la Argentina. Así, Daus destacó los casos del valle inferior del río Colorado, el valle del río Negro, los oasis cuyanos, y las comarcas del NOA y NEA aptas para cultivos subtropicales. La preocupación de Daus por la estrategia agraria del país no surge con este libro. Ya había abordado el tema en su artículo de 1939.

Si bien la idea global propositiva expuesta en 'El desarrollo argentino' es consistente, no deja de ser vaga, aún cuando la intención es delinear un "programa concreto de posibilidades", según expresa Daus en la introducción. La parte del libro más destacable es el análisis de la historia económica. El factor territorial flota a lo largo de todo el libro pero en pocos casos se logra ver sus significatividad.

En 1971 aparece 'El 'subdesarrollo' latinoamericano'. En este libro Daus demuestra nuevamente su habilidad para el tratamiento de los grandes temas macro. En una primera parte analiza el contenido de los conceptos de "desarrollo" y "subdesarrollo" y su aplicabilidad en el caso de la América latina. La precisión con la que Daus desarma y rearma estas nociones, y su total vigencia actual bajo otros términos, en la tan mentada globalización, mantienen este libro como de gran interés. En un artículo posterior señala que:

“... ambas situaciones, desarrollo y subdesarrollo, así como las categorías intermedias, por ser complejas y abarcar desde el medio espacial hasta el comportamiento del hombre en sus actitudes con respecto del mundo geográfico, se descomponen en incontables correlaciones y dependencia de localizaciones estructuradas". (DAUS, 1977, p. 259).

Como puede reconocerse, Daus cultivó a lo largo de toda su carrera un perfil claramente humanista, expandido luego hacia la macroeconomía. Su libro "Desarrollo y comportamiento" (1976b) puede considerarse ya como un trabajo de antropología/sociología política. Allí se analiza 
las posibles relaciones entre las mentalidades y culturas de grandes grupos, con el desarrollo. El énfasis está puesto sobre los caracteres de la personalidad de grandes grupos culturales del mundo. Sería difícil decir que este libro versa sobre una temática territorial. Pero sí tiene relación con un tema central tanto en 'Geografía y...' como en 'El desarrollo argentino': la proyección política de la Argentina en el marco del consenso de la unidad. De este libro puede destacarse el análisis del prototipo del 'caudillo', y su impacto en la historia nacional: la preeminencia absoluta de lo local para este prototipo, y la descripción de su relación, sólo circunstancial, con mayores niveles de integración política.

\section{Reflexiones finales y conclusión:}

Daus estableció un puente entre la cultura y la forma en que los argentinos encaramos las cosas comunes. La cultura sobre la que trabaja es la que se enraíza en el conocimiento del territorio, en forma integrada, sintética: aquí son protagonistas los más destacados rasgos, que sustancian este patrimonio común con tan sólo algunos trazos. Poco y bueno. Lo poco permite el acceso para cada uno de sus habitantes a una idea del propio territorio, sin deshacerse en disquisiciones presentadas solemnemente. Este es el primer elemento político que aborda Daus. El territorio pasible de ser apropiado por la totalidad de sus habitantes. De aquí que en su obra, como puede advertirse en su artículo de 1935, lo regional, lo didáctico y lo espistemológicamente específico van de la mano.

El segundo elemento es la inserción del territorio en la línea de tiempo. En este plano, el pensamiento de Daus se dirige directamente a dar sentido espacial a nuestra historia, que hasta entonces venía rezagada en este sentido, al menos respecto a dos vecinos del país: Chile y Brasil. Estos países con quienes nos tocó transitar el deslinde de fronteras, han dado a la comprensión de su origen una articulación con la formación del territorio.

En el primer caso, desde su percepción como limitante o recursos escaso. Puede decirse que aquí la política va delante del conocimiento científico, forjando una sensibilidad que enfoca lo territorial como una deuda de los chilenos consigo mismos. Al día de hoy se producen en este país reflexiones sobre el tema desde fuera del ámbito humanista o académico (EBENSPERGER $Y$ HERNÁNDEZ, 2010), lo cual podría estar reflejando la vigencia sostenida de esta vivencia restrictiva del propio territorio. 
En el Brasil, en cambio, lo territorial se entrelaza en forma positiva con el estudio del origen nacional. En este país el pensamiento de la propia historia establece sus primeros capítulos de la mano de la conformación del espacio integrado al dominio portugués. La obra dirigida por Sergio Buárque de Holanda (1961), si bien no puede señalarse como definitivamente representativa de la totalidad historiográfica brasileña, puede, al menos, ofrecerse como representativa de una historia territorializada, por el prestigio del director y por la amplitud de autores y temas que alcanzó. En la primera parte del primero de sus nueve volúmenes, al menos son cuatro los capítulos dedicados a la formación del territorio americano de Portugal. La autoría de uno de estos, as Monçoes, es del mismo Buárque de Holanda. Comparte aquí con Daus la afición al lenguaje compacto, aunque con mayor manejo estético. Tratándose de un historiador, sorprende la similitud con el planteo de "Geografía y unidad argentina". El sentido de lo acumulativo de la historia sobre el territorio es el mismo. El texto se dirige en forma predominante a esa horizontalidad de la superficie terrestre que simultánea a través de largos períodos de tiempo en las etapas fundacionales. Aquí, los razonamientos de Buárque de Holanda también buscan el libre juego de las fuerzas geográficas. El territorio no alcanza un primer plano por lo adverso (riesgo de ataques, enfermedades, aridez), o por lo desconocido, que viene a resaltar el coraje de los exploradores. El territorio es el elemento principal que el presente hereda de aquellas etapas fundacionales y, por lo tanto es el puente con aquellos siglos. El territorio es, de esta forma, el insumo de la historia temprana que hoy forma parte de la identidad. En la Argentina, este enfoque llegó a plasmarlo Daus y, en forma incipiente, el historiador Julio Irazusta en su "Breve historia de la Argentina", cuando trata los primeros siglos del Río de la Plata, tema que no abordado en otra parte de su obra (LASCANO, 2012).

Se trata de un "modelo americano" de participación del territorio en la identidad política de los países. Así, la conformación del territorio se adscribe a las etapas fundacionales, a aquellos tiempos tenidos por lejanos, cuando aún ni siquiera pueden rastrearse las circunstancias que llevarán a las independencias, o el perfil de sus protagonistas. El territorio es entonces un ciclo inicial, y como tal, esto es, seguido de etapas en las que la política se dirimió en otros planos de la realidad, es también un ciclo cerrado. Es lo que comparten Daus y Buárque de Holanda.

Paradójicamente, es la geografía, con planteos como el de Daus, la que puede aumentar la vivencia que los argentinos tenemos de las etapas más remotas de nuestra historia. Historia carente de proyección hacia los siglos españoles y excesivamente marcada por un comienzo instantáneo a partir de la independencia en 1810 (LESSER, 2003). 
En marcado contraste, queda trunco en Daus un desarrollo pleno de la aplicación práctica del conocimiento del territorio, el que puede adscribirse a la temática del desarrollo. A partir del momento en que asume cargos institucionales deja de lado la perspectiva expuesta en "Los bosques del Chaco", "El medio geográfico como fuente de riqueza” y “Extensión de la zona cereal argentina". En estos trabajos se realizan agudas observaciones sobre aspectos concretos de cada actividad económica. Cabe destacar aquí los fuertes puntos de contacto que estos temas tienen con la perspectiva de Alejandro Bunge y su grupo (GONZÁLEZ BOLLO, 2012).

Muy diferente es el nivel de análisis en "El desarrollo argentino". Allí se presenta una suerte de compendio de historia económica, intercalada con información de tipo sociológico; el tono es fuertemente académico. El desarrollo es abordado como categoría humanista. En los dos libros siguientes solo se progresará en esa dirección, y hacia el final, en "Desarrollo y comportamiento", Daus intenta establecer la relación entre una sociología de las mentalidades, la actividad económica y la construcción política, sin duda, un plan de trabajo ambicioso. ¿Habrá pasado por aquí más de una conversación con De Aparicio? El nivel de síntesis propuesto es varios órdenes de magnitud mayor al que guía "Los bosques del Chaco", rozando ya la filosofía. A pesar de todos los intentos por pragmatizar la geografía, gana en Daus un profundo humanismo, aunque siempre combinado con la búsqueda de caminos para la Argentina. En definitiva, la madurez muestra profundidad, pero dentro del mismo eje de los inicios.En "Desarrollo y comportamiento", último escalón en la evolución de su pensamiento, se indaga en las grandes culturas con un solo objetivo: comprender mejor a la Argentina y a los argentinos.

Fueron dos entonces los andariveles por los que transitó el pensamiento de Federico Daus. Caben para su obra las palabras que él mismo usó para describir el panorama de los estudios geográficos en la Argentina a comienzos de la década del '50, momento en el que su opinión asumía más el carácter de proposición o incluso descripción de su propia trayectoria, que de diagnóstico:

"La geografía ha logrado un lugar en el currículum universitario de la Argentina, ya sea como ciencia de aplicación, en los estudios de ciencias económicas, y como ciencia pura en las Facultades de Humanidades y de Filosofía y Letras." ". (DAUS, 1953, p. 5).

\section{REFERENCIAS:}

BARBA, E; Don Pedro de Cevallos. Rioplatense. Buenos Aires. 1978

BOERO, J.; Geografía de la Nación Argentina. Buenos Aires. Estrada. 1933 
BRITANNICA; Argentina. Tomo I knowledge in depth. 1981a.

BRITANNICA; Laski, Harold. Tomo VIII, knowledge in notice. 1981b.

BUÁRQUE DE HOLANDA, S.; As Monçoes. In: História da civilizaçao brasilera (Organizado por Sérgio Buárque de Holanda) tomo I. San Pablo. Bertrand Brasil. 1961.

CASTELLANOS, A; Fuente originarias del río Salado. Anales G/EA XI: 131-170. 1961.

DAUS, F.; Hidrografía de la cuenca del río Negro. Monografía presentada para optar al cargo de profesor suplente de Geografía Física. Inédito. 1927.

. Geografía Regional. Boletín del Colegio de la Universidad Nacional de La Plata 19, 1: 8997. 1935.

. La hidrografía de la región endorreica del Noroeste argentino. Anales GAEA VI: 207-225. 1938.

. El poblamiento de la Argentina. Servir 32: 3-24.1939.

. Rasgos geográficos del Nuevo Mundo. In: Historia de América (organizado por Ricardo Levene),Tomo I, 3-80. Buenos Aires. Jackson. 1940a.

. Los bosques del Chaco. Humanidades (La Plata) 28: 139-201. 1940 b.

El medio geográfico como fuente de riqueza. Cursos y conferencias 17, 8: 2130-2149. 1940c.

- Población de los oasis ricos y de los oasis pobres de la región árida argentina. Humanidades (La Plata) 29, 53-63. 1944.

. Extensión de la zona cereal argentina. Anales G/EA VII: 377-382. 1945a.

. Geografía de la Argentina I: parte física. Estrada. Buenos Aires. 1945b.

- Morfografía general de las llanuras argentinas. In: G/EA Geografía de la República Argentina (Organizado por Elina González Acha de Correa Morales) t III, 115-198. 1946b.

. Trashumación de montaña en Neuquén. Anales G/EA VIII: 383-426. 1948a. 
. Argentina. En Vidal de la Blache, P.; Gallois, L., Geografía Universal, T XXII. Montaner y

Simón. Barcelona. 1948b.

. La supuesta captura del río Fénix. Publicación del Instituto de Geografía Serie A, no 1 .

Facultad de Filosofía y Letras. Universidad de Buenos Aires. Buenos Aires. Buenos Aires. 1950.

. Reseña sobre historia de los conocimientos geográficos de la Argentina. Geográfica IPGH

$\mathrm{XI} / \mathrm{XII}, 31-36:$ 1-5. 1952

- Fisonomía Regional de la Argentina. Geográfica . Instituto Panamericano de Geografía e

Historia. Manual de Geografía, pub. no 212. 1956

. Geografía y unidad argentina. Nova. Buenos Aires. 1957.

. La transformación del paisaje natural en paisaje cultural antes de la Revolución de Mayo.

Anales GAEA XI: 1-17. 1961.

. La geografía aplicada. Boletín G/EA 51-55: 1-8. $1961 b$.

. Viajeros, geógrafos y sociedades geográficas. Boletín G/EA 52-55: 1-8. 1962a.

. ¿Qué es la geografía?. Columba. Buenos Aires. 1962b.

. Geografía de las fronteras. Revista de Gendarmería Nacional 16-19, varias páginas. 1966,

1967a, 1967b, 1967c.

. ¿Geografía sistemática o geografía regional en la enseñanza media? Anales GAEA XIII: 36-

50. 1969a.

. El desarrollo argentino. Editorial Universitaria de Buenos Aires. Buenos Aires. 1969b.

Fundamentos para una división regional de la Argentina. Publicación del Instituto de Geografía "Romualdo Ardissone". Serie A no 28. Facultad de Filosofía y Letras. Universidad de Buenos Aires. Buenos Aires. 1969c.

. El "subdesarrollo latinoamericano". El Ateneo. Buenos Aires. 1971. 
. Prólogo. In: Rey Balmaceda, R. Geografía histórica de la Patagonia. Cervantes. Buenos Aires. 1976a.

. Desarrollo y comportamiento. El Ateneo. Buenos Aires. 1976b.

- De la geografía cuantitativa a la geografía del comportamiento. In: Teoría de la Geografía" (organizado por Patricio Randle). GÆEA. Buenos Aires. 1977.

. La conciencia territorial de los argentinos y su raíz geográfica. In: La conciencia territorial (organizado por Patricio Randle). Oikos. Buenos Aires. 1978.

. El ámbito pampeano. In: "Atlas de Buenos Aires", (organizado por Horacio Difrieri) tomo I. Municipalidad de Buenos Aires. Buenos Aires. 1981.

EBENSPERGER, K; HERNÁNDEZ, C.; Temas limítrofes de Chile y sus vecinos. Diario "El Mercurio", 13/11/2010. 2010.

G. de GUTIÉRREZ, T.; Geografía general, astronómica y física. Librería de A. García Santos. Buenos Aires. 1929.

GÆEA; Libro de Actas, T III inédito. 1940-1950.

GONZÁLEZ BOLLO, H.; La teodicea estadística de Alejandro E. Bunge (1880-1943). Imago Mundi. UCA. Buenos Aires. 2012.

HALL, P.; Cities of tomorrow. Blackwell. Oxford. 2002.

IRAZUSTA, J.; Breve historia de la Argentina. Independencia. Buenos Aires. 1981.

LASCANO, M.; (2012). Realismo político y territorio. In: Historia y política en Julio Irazusta (organizado por, Marcelo . Ramón. Lascano). La Ley. Buenos Aires.

LASCANO, M.; CURTO, S.; El territorio como puente entre cultura y política, parte I. La trayectoria de Federico A. Daus, 1922-1957. Revista do Departamento de Geografia - USP v. 26: 15-37..

LESSER, R; Los orígenes de la Argentina: historias del Reino del Río de la Plata. Biblos. Buenos Aires. 2003. 
PASOTTI, P.; El arroyo Pavón. Morfología de su cuenca y modelo de red hidrográfica. Instituto de Fisiografía, Universidad Nacional de Rosario. Rosario. 1971.

POPOLIZIO, E.; El Paraná, un río y su historia geomorfológica. Tesis Doctoral. Universidad del Salvador. 2 tomos. Inédito. 2003.

RANDLE, R.; Personalidad y Obra de Federico A. Daus. Revista del IGM 5: 10-12. 1988.

REY BALMACEDA, R.; Federico Daus 1901-1988. Boletín G/EA 108: 2-6. 1990.

SABÍN PAZ, A.; Curso de geografía física. Biblioteca del Suboficial. Ejército Argentino. Buenos Aires. 1945.

SOLDANO, A.; Régimen y aprovechamiento de la red fluvial argentina. 2 tomos. Cimera. Buenos Aires. 1947.

VIDIRI, F., DAUS, F.; Observaciones sobre el estado de la vivienda en el Nordeste argentino. La habitación popular 12: 23-29. 1936.

VILLALOBOS R., S.; Comercio y contrabando en el Río de la Plata y Chile. EUDEBA. Buenos Aires. 1967.

ZAMORANO, M.; Geografía y unidad argentina. Recensión. Boletín de Estudios Geográficos UN Cuyo, 21: 158-160. 1958.

Artigo submetido em: 06/08/2013

Artigo aceito em: 30/06/2014 